\title{
Rice crops research according to remote sensing data (overview)
}

\author{
Michael Skazhennik ${ }^{1, *}$, Vitaly Chizhikov ${ }^{1}$, Anna Shevchenko², and Andrey Migachev ${ }^{2}$ \\ ${ }^{1}$ Federal Scientific Rice Centre, 3 Belozerny, Krasnodar, 350921, Russia \\ ${ }^{2}$ Institute of Control Sciences RAS., Profsoyuznaya Street, 65, Moscow 117997, Russia
}

\begin{abstract}
The introduction of precision farming technologies using hightech equipment will increase the productivity of rice, reduce its cost, and improve the environment. The use of digital technologies in agriculture is especially relevant in the face of rising prices for seeds, fertilizers and fuel, as it helps to significantly reduce costs and increase the profitability of agribusiness. The paper reviews the use of unmanned aerial vehicles (UAV) in rice cultivation and describes methods for assessing the state of rice crops. Drones are a more versatile and efficient tool for obtaining data on the state of crops of crops compared to information obtained from satellite images. They allow real-time monitoring of the most important indicators of the state of crops, which allows agricultural producers to make timely decisions. The UAV was used to determine the boundaries of the rice system, terrain, microreliefs of checks, moisture of the surface soil layer and the state of rice crops. The studies were carried out on a test site of the Federal State Budgetary Scientific Institution "Federal Scientific Rice Centre" with an area of 327 hectares. The main cultivated crop is rice variety Flagman. The survey was performed by a quadcopter with a Mica Sense Red Edge-M multispectral camera mounted on a fixed suspension. The shooting period using an unmanned aerial vehicle (UAV) was limited to early June and additionally used the Sentinel-2A satellite data covering the entire analyzed period (06.05.2019 - 08.29.2019). To assess the state of rice crops, the normalized relative vegetative index NDVI was used. Based on the NDVI distribution and yield information from the combine TUCANO 580 (CLAAS), a statistical analysis was carried out in fields 7 and 9. Testing of the experimental methodology for monitoring crops in 2019 on the basis of remote sensing of test plots and geoinformation modeling and the statistical apparatus should be considered satisfactory.
\end{abstract}

\section{Introduction}

For the effective use and management of vast areas of agricultural land in Russia, one should proceed from the principles of precision farming, relying on scientific research and technological progress. [1] This approach is not only able to reduce labor and time costs of farmers, increase crop yields, but also can improve the quality of products while reducing the environmental burden on the environment.

\footnotetext{
*Corresponding author: sma_49@mail.ru
} 
The use of unmanned aerial vehicles (hereinafter referred to as UAVs) in crop production is one of the most relevant and effective methods of precision farming [2]. Based on aerial photographs by means of UAVs and special programs, it is possible to create digital maps of fields in the form of orthophoto and vector plans; elevation and relief maps; determine the area of the contours; monitor the state of soils; calculate vegetation indices and predict yields; to carry out an inventory of agricultural lands, etc. [3, 4] In addition to monitoring, UAVs are successfully used in crop production when treating crops against diseases and pests. When applying chemicals and fertilizers, UAVs show a relatively low cost and high efficiency compared to traditional methods [5, 6].

This paper discusses the possibilities of using UAVs for monitoring in a specific field of crop production - rice growing. According to analysts, in the long term, an increase in demand for milled rice is expected, with market saturation being provided by domestic production. The main reserves for the growth and development of rice growing in the territory of the Russian Federation, in addition to modernizing production and improving rice-growing complexes, is the introduction of modern technologies and scientific research [7].

In the Russian Federation, rice is cultivated on engineering irrigation systems with artificial water supply to the main and accompanying crops. The key rice growing region is Krasnodar region, the rice system occupies 234 thousand hectares [8]. Rice is sown in small fields called checks, fenced with rollers. Together with canals, they form a complex system of irrigation fields. One of the factors of the production process is the leveling of rice fields, failure to comply with which entails the spread of weeds, which in turn will lead to a decrease in yield.

It should be noted that the construction of irrigation systems was inevitably accompanied by terracing of the natural relief, which is one of the reasons for the unsatisfactory irrigation and drainage state of soils. Under the influence of periodic flooding, the soils of rice fields differ from rainfed ones in heterogeneity and complexity of the physical, chemical and biochemical processes occurring in them. [9].

Due to the tension of the anthropoecological situation on irrigated systems in the rice growing zone, it is necessary to develop and introduce modern scientifically grounded elements of rice cultivation technology, which will reduce the environmental load [10].

Based on the foregoing, it is necessary to apply modern scientific and technical developments to create digital systems for assessing the state of a set of measures in the management of agricultural processes.

The use of UAVs for geoinformation monitoring of rice fields is one of the modern elements in rice cultivation technology aimed at increasing production processes and reducing the environmental burden on the environment by optimizing the use of plant protection products.

Analysis of literature data on the use of UAVs in agricultural production highlights the main areas of research, one of which is the forecast of rice yield based on various models for assessing vegetation indices based on multispectral images using various methods of data analysis [11-13]. Another important direction is the assessment of the state of agrocenoses on the basis of their optical and biological properties in the main phenological vases of the development of rice plants. [14, 15].

Purpose of the work: to analyze cartographic data on the spatial distribution of soil cover and plant biomass. 


\section{Materials and Methods}

The flights were carried out on the experimental field of FSBSI "Federal Scientific Rice Centre" (Belozerny, Krasnodar region) from February to June 2019. The total area of the rice system was 273 hectares. Rice variety Favorit was cultivated in the studied fields.

Unmanned aerial vehicles (UAVs) of aircraft and rotary types, equipped with cameras of the visible and near infrared range, and a multispectral camera were used. The flight altitude was $150 \mathrm{~m}$. In parallel, a geodetic survey of the territory was carried out (placement of control and reference points - 4 units, coordination of the flight base - 1 unit). Crossover $75 \%$. The UAV survey period was limited to the beginning of June; additionally, data from the Sentinel-2A satellite were used, covering the entire analyzed period (05.06.2019 29.08.2019).

To assess the state of rice crops, we used the normalized diference vegetation index (NDVI) [26].

The rice was harvested with a TUCANO 580 harvester of the German company CLAAS equipped for harvesting rice. The yield data of the studied fields is obtained from the CLAAS TELEMATICS cloud system in the form of a geospatial distribution of rice yield values on a cartographic basis.

The obtained data on the geospatial distribution of NDVI and rice yield were processed by methods of mathematical statistics.

\section{Results and Discussion}

\subsection{Determination of rice system boundaries and clarification of checks areas}

The problem was solved based on aerial photography data dated 16.02.2019 in the visible range of an aircraft-type UAV at an altitude of $300 \mathrm{~m}$, an accuracy of $5 \mathrm{~cm}$ per pixel. The obtained images were stitched together using the Agisoft Metashape photogrammetric program. In order to analyze aerial photographs, the construction of a raster, a matrix of heights, and specific matrices was further carried out.

The creation of a map of the experimental site (Fig. 1) was carried out in the geoinformation program "Neva" developed by the Russian Institute for Management Problems named after Trapeznikov? Moscow. With the help of this program, the area of the experimental fields was determined, based on their contours, created from the raster of the aerial photography obtained using the UAV.

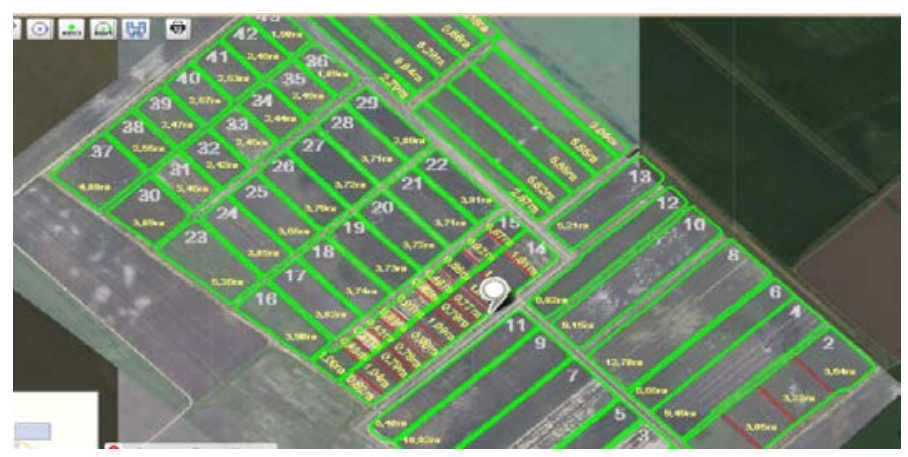

Fig. 1. Map of the experimental site divided into checks and indicating the areas of checks in hectares 
The use of UAVs makes it possible to monitor agricultural fields within the framework of which it is possible to carry out: clarification of the boundaries of cultivated fields and their inappropriate use; identify cadastral errors; assessment of the state of soils and agrophytocenoses [16].

Let us note the advantages of aerial photography from UAVs in relation to the use of satellite images:

- High variable resolution of shooting for the required tasks. High accuracy of satellite images is provided only on paid services, but there is always a possibility of artifacts on the map;

- Possibility of obtaining images with the required flight frequency - the efficiency of shooting. Space images may not match the desired shooting date;

- UAV flight does not depend on weather conditions (except for wind over $20 \mathrm{~m} / \mathrm{s}$ and snow shower), it flies under the edge of clouds. Satellite imagery is affected by cloudiness;

Updating the borders and areas of agricultural land using UAVs provides farmers with operational information about the actually cultivated land in comparison with accounting data.

\subsection{Monitoring of terraces of checks of rice irrigation system}

The advantage of aerial photography using UAVs is the acquisition of terrain data. For rice growing, this fact should be correlated with such concepts as terracedness and microrelief of a rice check.

The construction of irrigation systems for the cultivation of lowland rice is inevitably associated with the terracing of the natural relief, while in the countries of traditional rice cultivation, the value of the elevation differences between their planes is no more than 0.10 $\mathrm{m}$. soils [17]. The evenness of the surface of rice paddies is a prerequisite for achieving the highest yield of rice crops and reducing the consumption of irrigation water.

It is possible to assess the state of evenness of the surface of rice paddies using digital terrain models. And in this case, conclusions about the evenness of the check can be made both visually using hypsometric maps (height difference maps in color), and mathematically - using the tools of the Neva GIS and Agisoft Metashape in combination. In Agisoft Metashape, such analysis can be performed using a matrix of heights, and in GIS "Neva" it is possible to carry out analysis from cartographic to direct analytical. In this case, hypsometry with a color transition is shown every $10 \mathrm{~cm}$ inside each meter (Fig. 2).

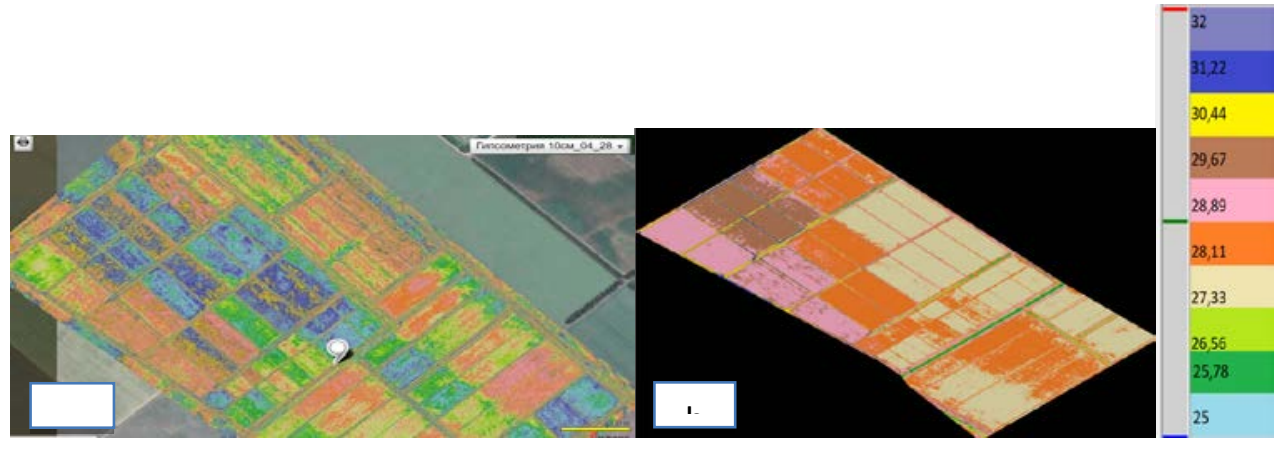

Fig. 2. Hypsometry of the rice system of FSBSI "Federal Scientific Rice Centre" dated 28/04/2019 
According to the visual analysis of the hypsometric map of the investigated experimental plot dated 28.04.2019, it was found that the height differences between the irrigation maps (areas of the rice crop rotation field, limited along the perimeter by the junior canals of the irrigation and drainage network) can reach $2 \mathrm{~m}$ (in Fig. 3, heights of $29.89 \mathrm{~m}$ and $27.88 \mathrm{~m}$ ).

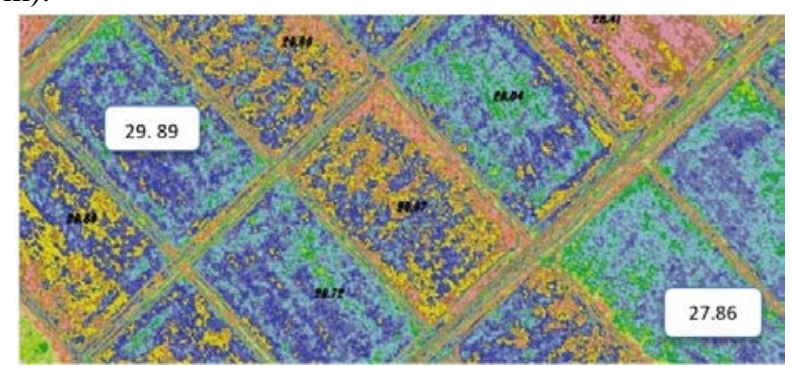

Fig. 3. Height differences on the hypsometry of the rice system

At the same time, the terraces between neighboring checks vary on average at the level of 20-30 cm. For an example of visualizing the terraces of neighboring checks, Figure 4 shows an irrigation map from the area of checks 17-22, 24-29.

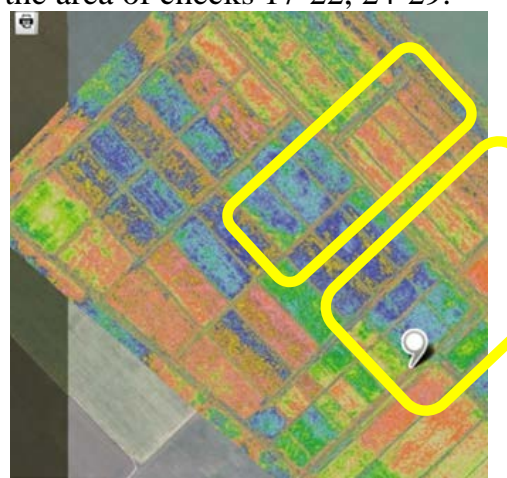

Fig. 4. Analysis of the terraces of neighboring checks using the example of the area of the studied rice system

Terrace according to scientific and expert data should be no more than $0.25-0.30 \mathrm{~m}$, and the maximum difference in check surface marks in the map should not be more than $1 \mathrm{~m}$ [18].

At the same time, it should be noted that in this case, the experimental site of FSBSI "Federal Scientific Rice Centre" was considered, where there was no goal of observing the terraced checks, this survey shows the possibility of monitoring the relief of any rice system.

Along with terraces, it is possible to analyze microreliefs of checks using a hypsometric map (see Fig. 5). Knowing the designation of the heights for each color and the set color step of $10 \mathrm{~cm}$, we can talk about the differences in the heights of the sections within this check by $20-40 \mathrm{~cm}$. 


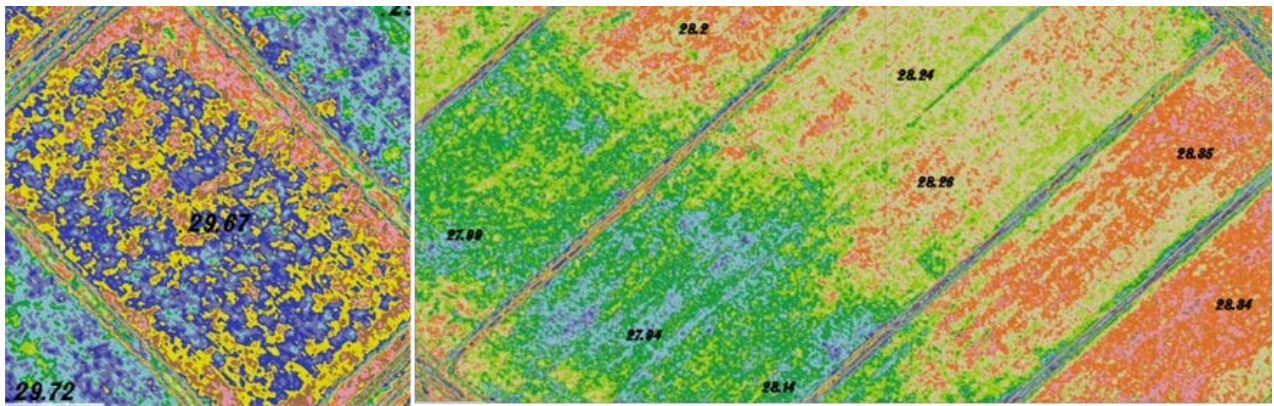

Fig. 5. Hypsometry of checks №33 and №3-9

The microrelief of checks affects the yield of rice and its weediness [19]. The more fluctuations in the marks of individual check points relative to its average mark, the lower the rice yield. [20,21]. Fluctuations in the microrelief marks of checks should not exceed \pm $5 \mathrm{~cm}$. The accumulated experience of growing rice confirms that irregularities in the surface of checks, which are within $\pm 10-13 \mathrm{~cm}$, lead to a decrease in rice yield by 1.5-2.7 times and an increase in irrigation water consumption 1.7-3.4 times [22, 23].

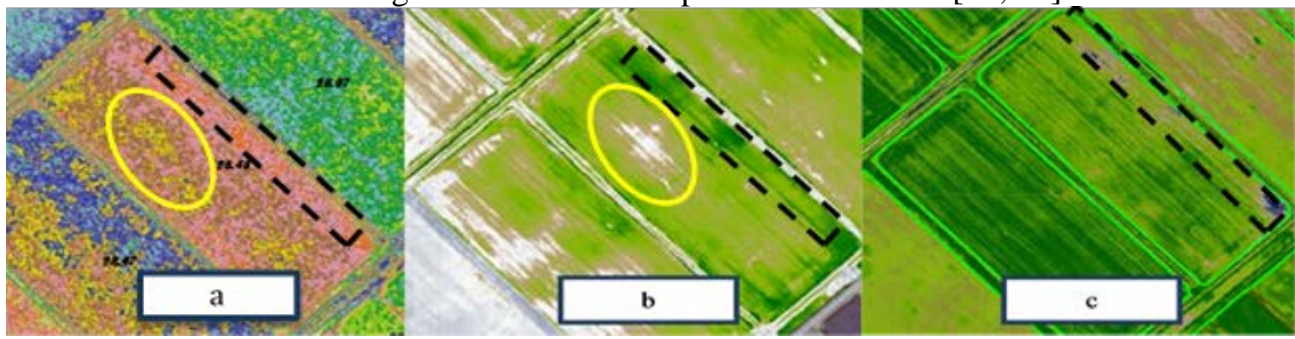

Fig. 6. Comparison of the check hypsometry before sowing with the moisture map and NDVI

On the microrelief of the check, orange areas are visible - a decrease in heights by 10-20 cm. (Fig. 6 a). In case of poor-quality leveling of the surface of the checks after the initial flooding and discharge, the water remains in low places for a long period, while in some areas the soil dries up. Rice seedlings develop unevenly under the water layer and not all of them overcome it, especially if it is large and the water temperature is high. On saline soils, dried bumps are a wick for pulling up salts, as a result, young rice seedlings in these areas completely die.

On the moisture map, the light areas represent a lack of moisture, in this area on the hypsometric map an increase in the microrelief of the check was observed on average at the level of $20 \mathrm{~cm}$. At the same time, the area of decrease in the microrelief of the check by an average of $10 \mathrm{~cm}$ (orange area) is characterized on the NDVI map by the absence or low values of this index, which is associated with a smaller number of plants per square meter from the optimal as a result of the death of a part of the plants during germination.

It should be noted that in this case, the possibility was investigated, based on the analysis of cartographic information in the GIS "NEVA", to create tasks for leveling machines in the form of a data array for the purpose of high-quality check alignment (with identification of areas requiring cutting or filling).

\subsection{Assessment of soil moisture}

The moisture content in the arable layer of the soil and the level of occurrence of groundwater in the complete absence of vegetation is of great importance at the beginning of field work. Long-term studies have proved the possibility of obtaining comparative 
estimates of the moisture content of the surface layer of the soil according to remote sensing data in the visible and IR ranges with sufficient soil homogeneity in terms of mechanical and chemical composition. A characteristic feature of vegetation and its condition is spectral reflectivity, characterized by large differences in the reflection of radiation at different wavelengths. The Water Ratio Index (WRI) is used to estimate the moisture content of vegetation. Calculated by the formula: WRI $=(G R E E N+R E D) /(N I R$ + SWIR2).

Below is the cartographic information on the moisture index of the selected study area of the rice system (Fig. 7) from the moment it is filled with water in order to analyze the flooding front of checks and further dynamics.

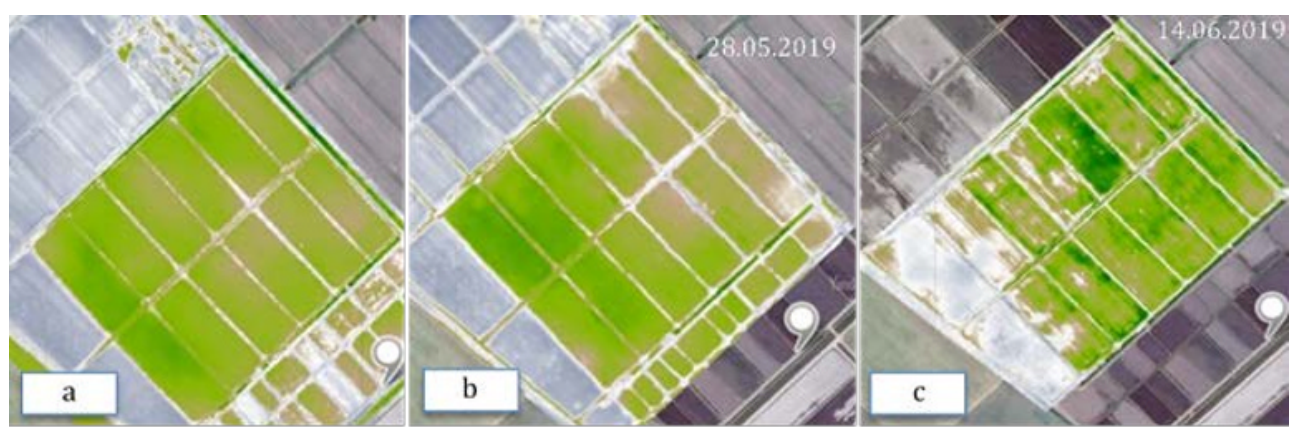

Fig. 7. Selected irrigation map of the rice system, a, b, c - shooting on different dates

Figure 8 shows the maps of the moisture index in dynamics, on which problem areas are visually distinguishable. When analyzing hypsometric data and moisture maps, a direct relationship is traced between the unevenness of the relief and the distribution of water in the selected area of receipts. On June 14, it is clearly seen that the water has gone from the highest checks (light areas) to the lower ones. The difference in heights on the upper group of checks (indicated by the black dotted line) reaches almost $1.5 \mathrm{~m}$ and it can be seen that the largest amount of water has accumulated in the lowest section, which indicates the presence of problem areas that require work to improve their reclamation state.

\subsection{Monitoring of the state of rice agrophytocenoses}

The statistical properties of the spatial distributions of the vegetation index and yield in the studied fields should be judged by the histograms (Fig. 8, 9) [24]. From a brief overview of the type of frequency distribution of variables, the following preliminary conclusions can be made. In field 7 (area $13.75 \mathrm{ha}$ ), histograms reflecting the distribution of the vegetation index according to the survey data from UAVs and the Sentinel-2A satellite at close dates at the beginning of June have incomparable forms; unites their multimodality. The latter property, found on independent data, may indicate the presence of some specific microscale factors that determine the spatial distribution of rice crops inside the field in June. At the end of August, the character of the NDVI distribution changes, which is also confirmed by the measurement data on field 9 (Fig. 6): the histogram becomes close to unimodal, with some negative asymmetry inherent in both fields (the left side is elongated), especially noticeable according to field 7 Our expectations of the closeness of the histogram forms reflecting the distribution of NDVI and yield were more likely to be confirmed than were disproved. In both cases, on the analyzed fields, the forms are visually close. (Fig. 8 c, d; Fig.9 c, d). 

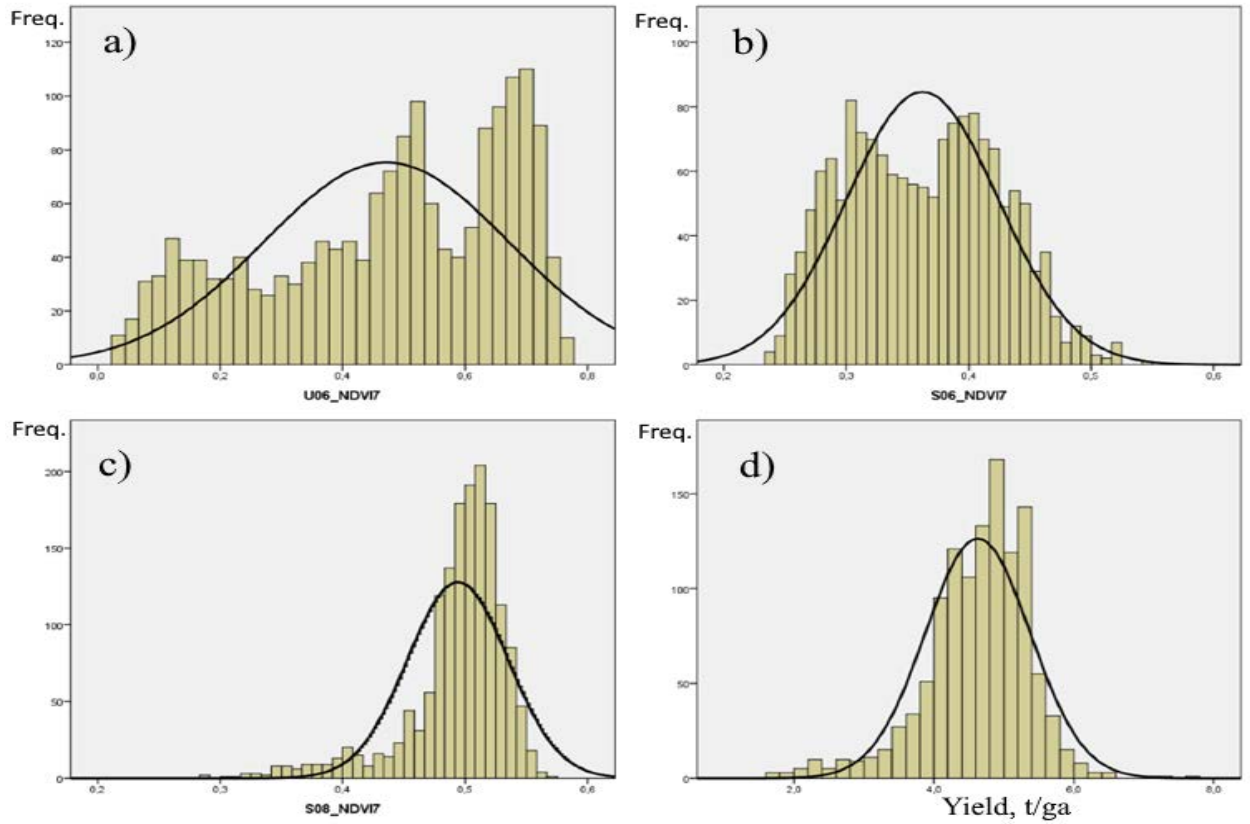

Fig. 8. Histograms of the distribution of the NDVI vegetation index on field 7 according to: a) BVS (06.06.2019), b) Sentinel-2A satellite (06.05.2019), c) Sentinel-2A satellite (08.29.2019), d) yield (September 12-14, 2019)
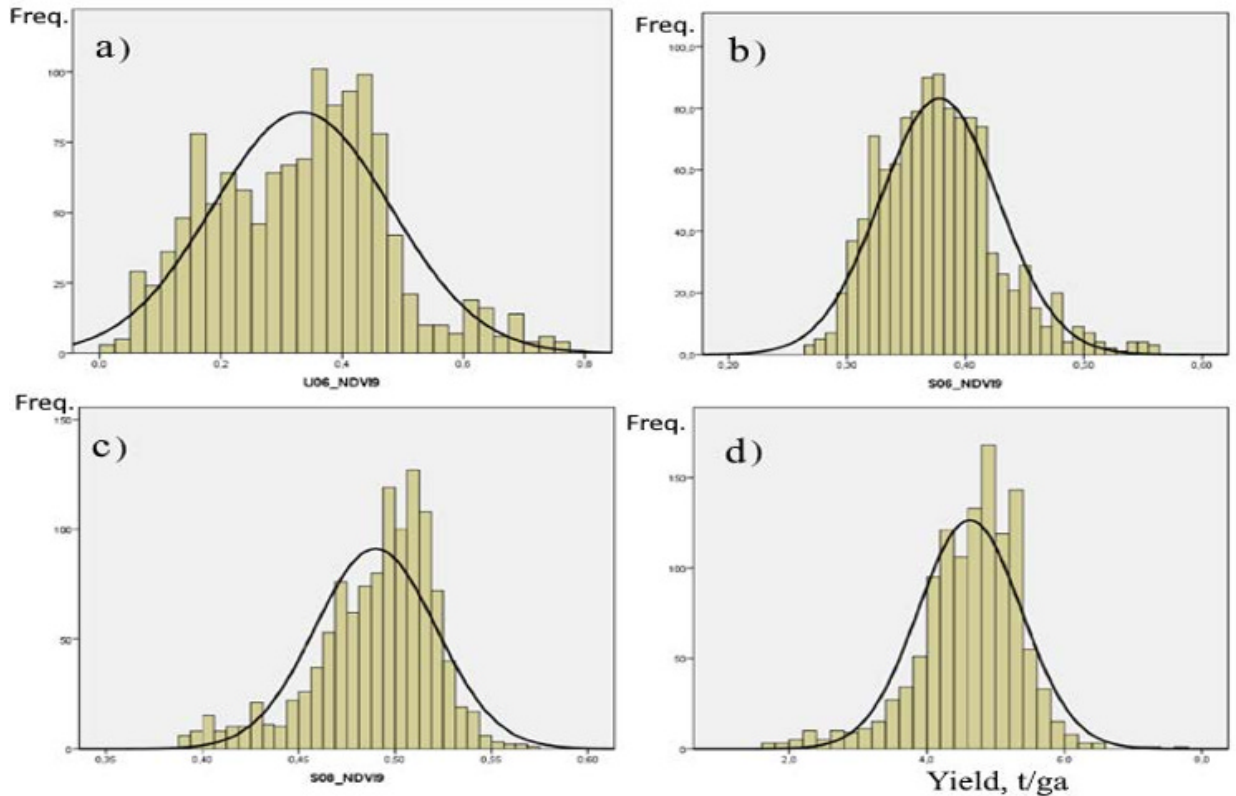

Fig. 9. Histograms of the distribution of the NDVI vegetation index on field 9 according to: a) UAVs (06.06.2019), b) Sentinel-2A satellite (06.06.2019), c) Sentinel-2A satellite (29.08.2019), d) productivity $(12-14,09.2019)$ 
At the same time, analysis of the correlation matrix of NDVI variables showed a statistically moderate and weak connectivity of the spatial distributions of the studied variables.

Studies based on the use of UAVs and Sentinel-2A satellite data make it possible to determine the degree of nitrogen supply to rice crops by optical indicators of their physiological state (NDVI), which are closely related to the yield map. Unmanned aerial vehicle (UAV) is a promising platform for remote sensing due to its versatility, and it is widely used to monitor the physiological state of rice crops and productivity [25]. Our data on the relationship of the optical-biological properties of rice crops with their productivity are generally consistent with reports of other authors [26, 27].

Thus, the possibility of determining the physiological state of rice crops by the optical properties of agrophytocenosis in the precision farming system is shown.

\section{Conclusions}

Since the impact of the anthropogenic factor on the soil is most pronounced during rice cultivation, it is necessary to conduct constant monitoring of the state of the rice system. UAVs are suitable for these purposes in terms of additional benefits, providing high-quality operational analytical information. Based on the analysis of cartographic data, it is possible to quickly solve problems in order to increase not only the volume of rice production, but also its quality while simultaneously reducing production and time costs.

Aerial photography data are suitable not only for assessing the current situation, but also for the accumulation of statistical data in order to conduct a comparative and integral analysis based on the results of the growing cycle of one or several years.

Based on the results of the research work, it was concluded that the use of UAVs, geographic information systems and computer technologies can solve the following tasks on rice systems: layout of rice paddies; evaluation of the relief of the rice system (terraces) and microrelief of checks; identification of WRI in the check; assessment of soil moisture; monitoring of the state of crops; identification of areas of crop loss; compilation of maps of NDVI; processing of crops.

\section{References}

1. S. Skubiev, D. Shapovalov, P. Lepekhin Experience of using UAVs for monitoring the state of rice crops in the Krasnodar Territory // Rice journal 4(41) (2018).

2. J. Barbedo A Review on the Use of Unmanned Aerial Vehicles // Drones 3(40) (2019).

3. N. Kurchenko, Ya. Ilchenko, E. Truflyak Development of software for processing images obtained from unmanned aerial vehicles. // KubSAU (2019).

4. M. González-Betancourt, M., Z.L Mayorga-Ruíz. Normalized difference vegetation index for rice management in El Espinal, Colombia // DYNA. 85 (2018) [Electronic resource]. URL: https://www.researchgate.net/publicati on/325406776_Normalized_difference_vegetation_index_for_rice_management_in_El_ Espinal_Colombia

5. Y. Seo, U. Shotaro Evaluating Farm Management Performance by the Choice of PestControl Sprayers in Rice Farming in Japan // Sustainability 13 (5) (2021)

6. Drones used in rice farming in central Vietnam // [Electronic resource] URL: https://vietnamnet.vn/en/sci-tech-environment/drones-now-used-by-vietnam-s-ricefarmers-595666.html (2020). 
7. Yu. A. Lysenko, I.N.Chuev, V.A. Khrisonid Problems and prospects of rice growing on the example of the Krasnodar Territory and the Republic of Adygea // Fundamental Research 4 (2019).

8. In the Kuban, the rice harvest was kept at the level of 2019 [Electronic resource] URL: https://tass.ru/ekonomika/9882401

9. O.A. Gutorova, A.Kh. Sheudzhen Ecological and agrochemical state of soils in rice agrolandscapes: monograph. - Maykop: (JSC "Polygraph-Yug", 2020).

10. S.A. Vladimirov, P.P. Meshcheryakov. Implementation of the bioclimatic productivity of the rice field // International scientific journal "Innovative Science" 1 (2018)

11.X. Zhou, H.B. Zheng, X.Q. Xu Predicting grain yield in rice using multi-temporal vegetation indices from UAV-based multispectral and digital imagery // ISPRS Journal $\begin{array}{lllll}\text { of Photogrammetry and Remote } & \text { Sensing. } 130 \quad \text { (2017) }\end{array}$ DOI:10.1016/j.isprsjprs.2017.05.003

12. Carlos A. Devia, Juan P. Rojas, T. Petro et al. High-Throughput Biomass Estimation in Rice Crops Using UAV Multispectral Imagery // Journal of Intelligent \& Robotic Systems 96, 11 (2019) DOI: 10.1007/s10846-019-01001-5

13. Bo Duan, S. Fang, R. Zhu, X. Wu et al. Remote Estimation of Rice Yield with Unmanned Aerial Vehicle (UAV) Data and Spectral Mixture Analysis // Front. Plant Sci. Feb (2019)

14. Qi Yang L.Shu, .J. Hun. et. al. A near real-time deep learning approach for detecting rice phenology based on UAV images // Agricultural and Forest Meteorology 287 (2020). https://doi.org/10.1016/j.agrformet.2020.107938

15. Sourav Kumar Bhoi, K.K. Jena, H.V. Long et. al. An Internet of Things assisted Unmanned Aerial Vehicle based artificial intelligence model for rice pest detection // $\begin{array}{lllll}\text { Microprocessors and } & \text { Microsystems } & \text { Feb } & 80 & \text { (2021) }\end{array}$ https://doi.org/10.1016/j.micpro.2020.103607

16. Russia A.ts.m. The use of spatial data for the formation of state information resources on agricultural lands 2019. - URL: https://pd.gosreforma.ru/wpcontent/uploads/2019/11/Report of the Analytical Center of the Ministry of Agriculture of Russia.pdf (2019)

17. V.A. Popov, N.V. Ostrovsky Agroclimatologists and Rice Ecosystem Hydraulics. Krasnodar: KubGAU, 2013.189 p.

18. N.R Magomedov. Resource-saving herbicide-free technology of rice cultivation in Dagestan // Rice growing. - 2019. - No. 2(43). - P. 57-60.

19. S.A. Vladimirov, I.A. Prikhodko, A.Yu.Verbitsky Improving the methods of irrigation of rice and crop rotation crops // Eurasian Union of Scientists (ESU) 4(61) (2019) DOI: 10.31618/ESU.2413-9335.2019.7.61.63

20. S.A. Vladimirov, S.V. Derkachev, A.S. Bezridny Planning and irrigation regime as factors of increasing the potential of the rice check // Collection of articles of the international scientific-practical conference: in 3 parts. Kazan. (2017)

21.F.A. Alekseenko, A.S. Bezridny, A.S. Vladimirov International scientific journal "Symbol of Science" 4 (2016)

22. G. Balakay, L. Dokuchaeva, R. Yurkova The problem of rate development of rice water consumption and water disposal from rice irrigation systems, Scientific journal of the Russian Research Institute of Melioration Problems, No. 3(31), (2018)

23. N. Ostrovskiy, V. Ostrovskiy, V. Shiskin Bull. Of the Nizhnevartovskiy agrouniversity complex: scince and higer professional education, No 3(47) (2017) 
24. S.V. Garkusha, M.A. Skazhennik, E.N. Kiselev, V.N Chizhikov and A.F. Petrushi Research of rice crops in Krasnodar region by remote sensing date. E3S Web of Conferences 175, 01004 (2020) INTERAGROMASH (2020)

25. Aidil P.P. Rizky, Mohamad Solahudin Liyantono Multi-copter development as a tool to determine the fertility of rice plants in the vegetation phase using aerial photos //Procedia Environmental Sciences 24. (2015)

26. S. Huang, Y. Miao, F. Yuan, X. Ma, X. et al. Satellite remote sensing-based in-season diagnosis of rice nitrogen status in Northeast China. Remote Sens. 7, 10646-10667. DOI:10.3390/rs70810646 (2015)

27. J. Lu, Y. Miao, W. Shi, et al. Evaluating different approaches to non-destructive nitrogen status diagnosis of rice using portable RapidSCAN active canonpy sensor. Sci. Rep. 7:14073. DOI:10.1038/s41598-017-14597-1 (2017) 